\title{
COMMON FIXED POINT THEOREMS FOR OCCASIONALLY CONVERSE COMMUTING MAPPINGS IN SYMMETRIC SPACES
}

\author{
${ }^{1}$ H. K. Pathak, ${ }^{2}$ R. K. Verma* \\ ${ }^{1}$ School of Studies in Mathematics, Pt. Ravi Shankar Shukla University \\ Raipur, 492010 (C.G.), India \\ ${ }^{2}$ Department of Mathematics, Govt. C. L. C. College Patan, Dist.-Durg \\ 491111 (C.G.), India \\ * Corresponding address: rohitverma1967@ rediffmail.com \\ Received 26 November, 2010; Revised 20 April, 2011
}

\begin{abstract}
In this paper, we introduce the notion of occasionally converse commuting (occ) mappings. Every converse commuting mappings ([1]) are (occ) but the converse need not be true (see, Ex.1.1-1.3). By using this concept, we prove two common fixed point results for a quadruple of self-mappings which satisfy an implicit relation. In first result one pair is (owc) [5] and the other is (occ), while in second result both the pairs are (occ). We illustrate our theorems by suitable examples. Since, there may exist mappings which are (occ) but not conversely commuting, the Theorems 1.1[2], 1.2[2] and 1.3[3] fails to handle those mapping pairs which are only (occ) but not conversely commuting (like Ex.1.4). On the other hand, since every conversely commuting mappings are (occ), so our Theorem 3.1 and 3.2 generalizes these theorems and the main results of Pathak and Verma [6]-[7]
\end{abstract}

Keywords and Phrases: commuting mappings, conversely commuting mappings, occasionally converse commuting (occ) mappings, set of commuting mappings, fixed point.

Mathematics Subject Classifications: 47H10, 54H25.

\section{INTRODUCTION}

$\mathrm{Lu}$ [1] presented the concept of converse commuting mappings and proved some common fixed point results. Liu and $\mathrm{Hu}$ [2] used this concept for multi-valued mappings. Popa [3] extended his result for the mappings satisfying an implicit relation.

DEFINITION 1.1 A symmetric on a set $X$ is a real-valued function $d: X \times X$ such that

(i) $\quad d(x, y) \geq 0$, for all $x, y$ in $X$ and $d(x, y)=0$ if and only if $x=y$.

(ii) $\quad d(x, y)=d(y, x)$.

Throughout this paper, unless otherwise stated, let $(\mathrm{X}, \mathrm{d})$ be a symmetric space; $\operatorname{com}(\mathrm{A}, \mathrm{S})$ denotes the set of commuting points, $\mathrm{C}(\mathrm{A}, \mathrm{S})$ denotes the set of coincidence points of $\mathrm{A}$ and $\mathrm{S}$, and $\mathrm{R}, \mathrm{Q}$ and $\mathrm{R} \backslash \mathrm{Q}$ are the sets of real, rational and irrational numbers, respectively.

DEFINITION 1.2 ([1]) Two self-maps A and S are called conversely commuting, if for all $x$ in $X$, the $A S x=S A x$ implies $A x=S x$. 
DEFINITION 1.3 Two self-mappings $A$ and $S$ are called occasionally converse commuting (occ), if for some $\mathrm{x}$ in $\mathrm{X}$, the $\mathrm{ASx}=\mathrm{SAx}$ implies Ax $=\mathrm{Sx}$.

Following example shows that, every conversely commuting mapping is (occ) but the reverse need not be true.

EXAMPLE 1.1 Let $X=R$ and the self-mappings $A$ and $S$ are defined by:

$A x=0$, if $x$ is a rational number, $\quad S x=0$, if $x$ is a rational number,

$A x=1$, if $x$ is an irrational number. $\quad S x=1$, if $x$ is an irrational except $\sqrt{ } 2$ or $\pi$,

$S x=2$, if $x$ is $\sqrt{ } 2$ or $\pi$.

If $x=x_{1}$ is $\sqrt{2}$ or $\pi$, then $A$ and $S$ are commuting but they do not coincidence at $x_{1}$. On the other hand, if $\mathrm{x}=\mathrm{x}_{2}$ is an irrational number except $\sqrt{2}$ or $\pi$, then $\mathrm{ASx}_{2}=\mathrm{SAx}_{2}=0$ implies $\mathrm{Ax}_{2}=\mathrm{Sx}_{2}=1$. Similarly, if $\mathrm{x}=\mathrm{x}_{3}$ is rational, then $\mathrm{ASx}_{3}=\mathrm{SAx}_{3}=0$ implies $\mathrm{Ax}_{3}=\mathrm{Sx}_{3}=0$.

Hence (A, S) is occasionally converse commuting (occ) and the set of (occ) is the set of real number except $\sqrt{ } 2$ and $\pi$. So that pair $(A, S)$ is not conversely commuting but it is (occ). It verifies that every conversely commuting mapping is (occ) but the reverse need not be true.

EXAMPLE 1.2 Let $X=R$ and the mappings $A$ and $S$ are defined by:

$A x=2$, if $x$ is a rational number, and $S x=2$, if $x$ is rational number,

$A x=3$, if $x$ is irrational number. $\quad S x=4$, if $x$ is an irrational number.

Then, the set of commuting points of $\mathrm{A}$ and $\mathrm{S}$ is $\operatorname{com}(\mathrm{A}, \mathrm{S})=\mathrm{R}$. But mapping $\mathrm{A}$ and $\mathrm{S}$ coincides only for the points of $\mathrm{Q}$. Hence the set of (occ) $=\mathrm{Q}$, and mappings $\mathrm{A}$ and $\mathrm{S}$ are occasionally converse commuting (occ).

EXAMPLE 1.3 Let $X=\{a, b, c, p\}$ be a finite set of $R^{2}$ with the Euclidean metric $d$, where $a=(0,0), b=(0,2), c=(1,0)$ and $p=(0,1 / 4)$. Define maps $A, B, S$, Ton $X \times X$ by: $\mathrm{Aa}=\mathrm{Ab}=\mathrm{a}, \quad \mathrm{Ac}=\mathrm{b}, \quad \mathrm{Ap}=\mathrm{c}, \quad \mathrm{Sa}=\mathrm{Sb}=\mathrm{a}, \quad \mathrm{Sc}=\mathrm{b}, \quad \mathrm{Sp}=\mathrm{a}, \quad \mathrm{Ba}=\mathrm{a}, \quad \mathrm{Bb}=\mathrm{b}, \quad \mathrm{Bc}=\mathrm{c}, \quad \mathrm{Bp}=\mathrm{p}$, $\mathrm{Ta}=\mathrm{Tb}=\mathrm{Tc}=\mathrm{a}$, and $\mathrm{Tp}=\mathrm{p}$.

Then, the set of commuting points $\operatorname{com}(\mathrm{A}, \mathrm{S})=\{\mathrm{a}, \mathrm{b}, \mathrm{c}\}$ and $\operatorname{com}(\mathrm{B}, \mathrm{T})=\{\mathrm{a}, \mathrm{b}, \mathrm{c}, \mathrm{p}\}=\mathrm{X}$ and the set of coincidence points of $A$ and $S$ is $C(A, S)=\{a, b, c\}$ and that of $B$ and $T$ is $\mathrm{C}(\mathrm{B}, \mathrm{T})=\{\mathrm{a}, \mathrm{p}\}$. Thus $\mathrm{B}$ and $\mathrm{T}$ coincide at some points of $\operatorname{com}(\mathrm{B}, \mathrm{T})$. Hence $(\mathrm{B}, \mathrm{T})$ is only occasionally converse commuting (occ) but not conversely commuting. Next, since A and $\mathrm{S}$ coincide at each commuting points so it is obviously conversely commuting, thus it is (occ) also.

DEFINITION 1.4 ([4]) Two self-maps A and S are called weakly compatible, if $\mathrm{ASx}=\mathrm{SAx}$ whenever $\mathrm{Ax}=\mathrm{Sx}$, for all $\mathrm{x}$ in $\mathrm{X}$.

The concept of weakly compatible mapping ([4]) was generalized to occasionally weakly compatible ([5]). 
DEFINITION 1.5 ([5]) Two self mappings $A$ and $S$ are called occasionally weakly compatible (owc), if ASx $=\mathrm{SAx}$ whenever $\mathrm{Ax}=\mathrm{Sx}$, for some $\mathrm{x}$ in $\mathrm{X}$.

Every weakly compatible mapping is (owc) but not conversely, (see [5]).

Liu and $\mathrm{Hu}$ [2], and Popa [3] proved the following common fixed point theorems for conversely commuting mappings. We like to generalize these theorems for (occ) maps.

THEOREM 1.1 ([2]) Let $\mathrm{f}, \mathrm{g}: \mathrm{X} \rightarrow \mathrm{X}$ be two conversely commuting mappings. Suppose that there exist a commuting point of $\mathrm{f}$ and $\mathrm{g}$, and

$$
d(f x, f y) \leq \psi(\max \{d(g x, g y), d(g x, f y), d(f y, g y)\}),
$$

for each $\mathrm{x}, \mathrm{y}$ in $\mathrm{X}$. If $\psi$ is non-decreasing on $\mathrm{R}_{+}$and $\psi(\mathrm{t})<\mathrm{t}$, for each $\mathrm{t}>0$, then there exists a common fixed point of $\mathrm{f}$ and $\mathrm{g}$.

THEOREM 1.2 ([2]) Let A, B, S, T: $\mathrm{X} \rightarrow \mathrm{X}$ be four self-maps satisfying:

$$
\mathrm{d}(\mathrm{Ax}, \mathrm{By}) \leq \psi(\max \{\mathrm{d}(\mathrm{Sx}, \mathrm{Ty}), \mathrm{d}(\mathrm{Ax}, \mathrm{Sx}), \mathrm{d}(\mathrm{By}, \mathrm{Ty}), \mathrm{d}(\mathrm{By}, \mathrm{Sx}), \mathrm{d}(\mathrm{Ax}, \mathrm{Ty})\}),
$$

for each $\mathrm{x}, \mathrm{y}$ in $\mathrm{X}$. Suppose that there exists a commuting point of $\mathrm{A}$ and $\mathrm{S}$, and a commuting point of $\mathrm{B}$ and $\mathrm{T}$. If $(\mathrm{A}, \mathrm{S})$ and $(\mathrm{B}, \mathrm{T})$ are conversely commuting mappings and if $\psi$ is non-decreasing on $\mathrm{R}_{+}$such that $0<\psi(\mathrm{t})<\mathrm{t}$, for each $\mathrm{t}>0$, then there exist common fixed point of $\mathrm{A}, \mathrm{B}, \mathrm{S}$ and $\mathrm{T}$.

THEOREM 1.3 ([3]) Let A, B, S, T: $X \rightarrow X$ be four self-maps satisfying

$$
\psi(\mathrm{d}(\mathrm{Ax}, \mathrm{By}), \mathrm{d}(\mathrm{Sx}, \mathrm{Ty}), \mathrm{d}(\mathrm{Ax}, \mathrm{Sx}), \mathrm{d}(\mathrm{By}, \mathrm{Ty}), \mathrm{d}(\mathrm{By}, \mathrm{Sx}), \mathrm{d}(\mathrm{Ax}, \mathrm{Ty})) \leq 0
$$

If $(\mathrm{A}, \mathrm{S})$ and $(\mathrm{B}, \mathrm{T})$ are conversely commuting, and $\mathrm{A}$ and $\mathrm{S}$ have a commuting point, and $\mathrm{B}$ and $\mathrm{T}$ have a commuting point, where $\psi\left(\mathrm{t}_{1}, \cdots, \mathrm{t}_{6}\right): \mathrm{R}_{+}{ }^{6} \rightarrow \mathrm{R}$ is such that $\psi$ is nonincreasing in variables $t_{2}, t_{5}, t_{6}$ and $\psi(t, t, 0,0, t, t)>0$, for all $t>0$, then there exist unique common fixed point of $\mathrm{A}, \mathrm{B}, \mathrm{S}$ and $\mathrm{T}$.

\section{IMPLICIT RELATIONS}

Let $\boldsymbol{F}_{6}$ be the set of all real-valued functions $\mathrm{F}\left(\mathrm{t}_{1}, \ldots, \mathrm{t}_{6}\right): \mathrm{R}^{6}{ }_{+} \rightarrow \mathrm{R}$ satisfying the following conditions:

$\left(F_{1}\right): \quad F$ is non-decreasing in variables $t_{2}, t_{5}, t_{6}$

$\left(\mathrm{F}_{2}\right): \quad \mathrm{F}(\mathrm{t}, \mathrm{t}, 0,0, \mathrm{t}, \mathrm{t})<0$, for each $\mathrm{t}>0$.

EXAMPLE 2.1 Let $\mathrm{F}\left(\mathrm{t}_{1}, \ldots, \mathrm{t}_{6}\right)=\mathrm{t}_{2}+\max \left\{\mathrm{t}_{3}, \mathrm{t}_{4},\left[\mathrm{t}_{5}+\mathrm{t}_{6}\right] / 2\right\}-\mathrm{kt}_{1}$, where $\mathrm{k}>2$.

Then $\left(\mathrm{F}_{1}\right)$ is obvious and $\left(\mathrm{F}_{2}\right)::=\mathrm{t}+\max \{0,0, \mathrm{t}\}-\mathrm{kt}<0$. So that $\mathrm{F} € \boldsymbol{F}_{6}$.

EXAMPLE 2.2 Let $F\left(t_{1}, \ldots, t_{6}\right)=-t_{1}+\phi\left(\max \left\{t_{2}, t_{3}, \ldots, t_{6}\right\}\right)$, where $0<\phi(t)<t$, for each $t>0$. Then $\left(\mathrm{F}_{1}\right)$ is obvious and $\left(\mathrm{F}_{2}\right):=-\mathrm{t}+\varnothing(\mathrm{t})<0$. So that $\mathrm{F} \in \boldsymbol{F}_{6}$. 
EXAMPLE 2.3 Let $F\left(t_{1}, \ldots, t_{6}\right)=-a_{1}{ }^{p}+b \cdot \max \left\{h_{5}{ }^{p}, k_{t}{ }^{p}\right\}+$ ct $_{2}{ }^{p}$ where a, b, c, h, k, p>0 such that a $>$ b.max $\{h, k\}+c$. Then $\left(F_{1}\right)$ is obvious and $\left(F_{2}\right):=t^{p}(-a+b \cdot \max \{h, k\}+c)<0$, for each $\mathrm{t}>0$. So that $\mathrm{F} \in \boldsymbol{F}_{6}$.

In this paper, we prove some common fixed point results which satisfy the above implicit relations, by using the occasionally converse commuting (occ) condition. Especially, in first result, we take one of the two pairs (occ) and another pair is (owc); and in the second result both pairs are occasionally converse commuting (occ). We illustrate our theorems by some suitable examples.

\section{RESULTS}

THEOREM 3.1 Let A, B, S, T: $\mathrm{X} \rightarrow \mathrm{X}$ be four self-mappings satisfying:

$$
\varnothing(d(A x, B y), d(S x, T y), d(A x, S x), d(B y, T y), d(B y, S x), d(A x, T y)) \geq 0,
$$

where $\mathrm{x}, \mathrm{y} € \mathrm{X}$ and $\varnothing € \boldsymbol{F}_{6}$. If one of the following conditions holds:

(i) the pair $(\mathrm{A}, \mathrm{S})$ is (occ) and the pair $(\mathrm{B}, \mathrm{T})$ is (owc), or

(ii) the pair $(\mathrm{B}, \mathrm{T})$ is (occ) and the pair $(\mathrm{A}, \mathrm{S})$ is (owc),

then $\mathrm{A}, \mathrm{B}, \mathrm{S}$ and $\mathrm{T}$ have a unique common fixed point in $\mathrm{X}$.

PROOF Suppose that pair (B, T) is occasionally weakly compatible (owc). Then, by definition, there exist some coincidence point $\lambda € \mathrm{C}(\mathrm{B}, \mathrm{T})$ such that $\mathrm{BT} \lambda=\mathrm{TB} \lambda$ whenever $\mathrm{B} \lambda=\mathrm{T} \lambda=\mathrm{Z}$ (say) where $\mathrm{C}(\mathrm{B}, \mathrm{T})$ denote the set of coincidence points of $\mathrm{B}$ and $\mathrm{T}$. So that for a given $\lambda$,

$$
\mathrm{Bz}=\mathrm{Tz} \text { whenever } \mathrm{B} \lambda=\mathrm{T} \lambda=\mathrm{z} \text {. }
$$

Next, since (A, S) is occasionally converse commuting (occ). Then, by definition, there exist some $\mathrm{u} € \mathrm{X}$ such that $\mathrm{ASu}=\mathrm{SAu}$ implies $\mathrm{Au}=\mathrm{Su}=\mathrm{w}$ (say). So that for a given $\mathrm{u}$,

$$
\mathrm{Aw}=\mathrm{Sw} \text { implies that } \mathrm{Au}=\mathrm{Su}=\mathrm{w} \text {. }
$$

We claim that $\mathrm{AAu}=\mathrm{Bz}$. If not, then putting $\mathrm{x}=\mathrm{Au}$ and $\mathrm{y}=\mathrm{z}$ in (4), and using $\mathrm{ASu}=$ $\mathrm{SAu}=\mathrm{AAu}$ and $\mathrm{Tz}=\mathrm{Bz}$, we obtain

$$
\varnothing(\mathrm{d}(\mathrm{AAu}, \mathrm{Bz}), \mathrm{d}(\mathrm{AAu}, \mathrm{Bz}), 0,0, \mathrm{~d}(\mathrm{AAu}, \mathrm{Bz}), \mathrm{d}(\mathrm{AAu}, \mathrm{Bz})) \geq 0,
$$

a contradiction of $\left(\mathrm{F}_{2}\right)$. Thus $\mathrm{AAu}=\mathrm{Bz}$. Therefore $\mathrm{Aw}=\mathrm{Bz}=\mathrm{Sw}=\mathrm{Tz}$.

We claim $\mathrm{Au}=\mathrm{Bz}$. If not, then putting $\mathrm{x}=\mathrm{u}$ and $\mathrm{y}=\mathrm{z}$ in (4), and using (5) and (6), we get

$$
\varnothing(\mathrm{d}(\mathrm{Au}, \mathrm{Bz}), \mathrm{d}(\mathrm{Au}, \mathrm{Bz}), 0,0, \mathrm{~d}(\mathrm{Au}, \mathrm{Bz}), \mathrm{d}(\mathrm{Au}, \mathrm{Bz})) \geq 0
$$

a contradiction of $\left(\mathrm{F}_{2}\right)$. Thus $\mathrm{Au}=\mathrm{Bz}$. Therefore,

$$
\mathrm{Au}=\mathrm{Bz}=\mathrm{Tz}=\mathrm{Su}=\mathrm{AAu}=\mathrm{SAu} .
$$


It follows that $\mathrm{Au}$ is a common fixed point of $\mathrm{A}$ and $\mathrm{S}$. Next, we claim that $\mathrm{Bz}=\mathrm{z}$. If not, then putting $\mathrm{x}=\mathrm{u}$ (given) and $\mathrm{y}=\lambda$ (given) in (4) and using (7), we obtain

$$
\varnothing(\mathrm{d}(\mathrm{Bz}, \mathrm{z}), \mathrm{d}(\mathrm{Bz}, \mathrm{z}), 0,0, \mathrm{~d}(\mathrm{z}, \mathrm{Bz}), \mathrm{d}(\mathrm{Bz}, \mathrm{z})) \geq 0,
$$

a contradiction of $\left(\mathrm{F}_{2}\right)$. Thus $\mathrm{Bz}=\mathrm{z}$. Therefore,

$$
\mathrm{Bz}=\mathrm{z}=\mathrm{Tz}=\mathrm{Au}=\mathrm{Su}=\mathrm{AAu}=\mathrm{SAu}
$$

Hence $\mathrm{z}$ is a common fixed point of $\mathrm{A}, \mathrm{B}, \mathrm{S}$ and $\mathrm{T}$.

For uniqueness, let $\mathrm{z}_{0}$ be another common fixed point of $\mathrm{A}, \mathrm{B}, \mathrm{S}, \mathrm{T}$ then by putting $\mathrm{x}=\mathrm{z}$ and $y=z_{0}$ in (4), we obtain a contradiction of $\left(F_{2}\right)$. Thus $A, B, S$ and $T$ have a unique common fixed point. The proof for alternative case is similar. This completes the proof.

Next, we prove the following result for both pairs occasionally converse commuting.

THEOREM 3.2 Let A, B, S, T:X $\rightarrow X$ be four self-maps satisfying condition (4), for each $\mathrm{x}$, y€ $\mathrm{X}$ and $\varnothing € \boldsymbol{F}_{6}$. If both the pairs $(\mathrm{A}, \mathrm{S})$ and $(\mathrm{B}, \mathrm{T})$ are occasionally converse commuting (occ), then $\mathrm{A}, \mathrm{B}, \mathrm{S}$ and $\mathrm{T}$ have a unique common fixed point in $\mathrm{X}$.

PROOF Let $\operatorname{occ}(\mathrm{A}, \mathrm{S})$ denote the set of occasionally converse commuting points of A and $\mathrm{S}$. Since the pair $(\mathrm{A}, \mathrm{S})$ is occasionally converse commuting, by definition, there exist some $\mathrm{u} € \operatorname{occ}(\mathrm{A}, \mathrm{S})$ subset $\mathrm{X}$; such that $\mathrm{ASu}=\mathrm{SAu}$ implies $\mathrm{Au}=\mathrm{Su}$. Hence $\mathrm{d}(\mathrm{Au}, \mathrm{Su})=0$. It follows that

$$
\mathrm{AAu}=\mathrm{ASu}=\mathrm{SAu} .
$$

Similarly, the occasionally converse commuting points for the pair $(\mathrm{B}, \mathrm{T})$ implies that there exist $\mathrm{v} € \operatorname{occ}(\mathrm{B}, \mathrm{T})$ such that $\mathrm{BTv}=\mathrm{TBv}$ implies $\mathrm{Bv}=\mathrm{Tv}$. Hence $\mathrm{d}(\mathrm{Bv}, \mathrm{Tv})=0$ and so

$$
\mathrm{BBv}=\mathrm{BTv}=\mathrm{TBv}
$$

Let us show that $\mathrm{Au}=\mathrm{Bv}$. If not, then putting $\mathrm{x}=\mathrm{u}$ and $\mathrm{y}=\mathrm{v}$ and using $\mathrm{d}(\mathrm{Au}, \mathrm{Su})=0$ and $d(B v, T v)=0$ in $(4)$, we obtain

$$
\varnothing(\mathrm{d}(\mathrm{Au}, \mathrm{Bv}), \mathrm{d}(\mathrm{Au}, \mathrm{Bv}), 0,0, \mathrm{~d}(\mathrm{Au}, \mathrm{Bv}), \mathrm{d}(\mathrm{Au}, \mathrm{Bv})) \geq 0,
$$

a contradiction of $\left(\mathrm{F}_{2}\right)$. Thus, $\mathrm{Au}=\mathrm{Bv}$. Next, we claim that $\mathrm{Au}$ is a fixed point of $\mathrm{A}$. Suppose not. Then, by putting $\mathrm{x}=\mathrm{Au}$ and $\mathrm{y}=\mathrm{v}$ in (4), we obtain

$$
\varnothing(\mathrm{d}(\mathrm{AAu}, \mathrm{Au}), \mathrm{d}(\mathrm{AAu}, \mathrm{Au}), 0,0, \mathrm{~d}(\mathrm{Au}, \mathrm{AAu}), \mathrm{d}(\mathrm{AAu}, \mathrm{Au})) \geq 0
$$
a contradiction of $\left(F_{2}\right)$. Thus $A u=A A u$. Similarly, $B v=B B v$. Since $A u=B v$, we have

$$
\mathrm{Au}=\mathrm{Bv}=\mathrm{AAu}=\mathrm{ASu}=\mathrm{SAu}=\mathrm{BBv}=\mathrm{BTv}=\mathrm{TBv}
$$


Therefore $\mathrm{Au}=\mathrm{w}$ (say), is a common fixed point of $\mathrm{A}, \mathrm{B}, \mathrm{S}$ and $\mathrm{T}$. For uniqueness, let $\mathrm{w}^{\prime} \neq \mathrm{w}$ be another common fixed point of A, B, S and T, then by (4), we have successively

$\varnothing\left(d(A w, B w 0), d\left(S w, T w^{\prime}\right), d(A w, S w), d\left(B w^{\prime}, T w^{\prime}\right), d\left(B w^{\prime}, S w\right), d\left(A w, T w^{\prime}\right)\right) \geq 0$

$$
\varnothing(d(w, w 0), d(w, w 0), 0,0, d(w 0, w), d(w, w 0)) \geq 0
$$

a contradiction. Thus $\mathrm{w}=\mathrm{w}^{\prime}=\mathrm{Au}$, and $\mathrm{Au}$ is a unique common fixed point of $\mathrm{A}, \mathrm{B}, \mathrm{S}$ and T. This completes the proof.

REMARK 3.1 As seen in Examples 1.1-1.3, there may exists mappings which are occasionally converse commuting (occ) but which do not conversely commute. Next, since every converse commuting mappings are occasionally converse commuting (occ), so our Theorems 3.1 and 3.2 generalizes Theorems 1.1, 1.2 and 1.3. It also generalizes the main results of [6] and [7].

\section{ILLUSTRATIVE EXAMPLES}

The following example validates our Theorem 3.1.

EXAMPLE 3.1 Consider Example 1.3. The pair (B, T) is occasionally converse commuting (occ) and (A, S) is (owc). So condition (ii) of Theorem 3.1 is satisfied. Now, suppose that $\mathrm{F}: \mathrm{R}_{+}{ }^{6} \rightarrow \mathrm{R}$ with $\mathrm{F}\left(\mathrm{t}_{1}, \ldots, \mathrm{t}_{6}\right)=\mathrm{t}_{2}+2\left(\mathrm{t}_{3}+\mathrm{t}_{4}\right)+1 / 2\left(\mathrm{t}_{5}+\mathrm{t}_{6}\right) \cdot \mathrm{kt}_{1}$, where $2<\mathrm{k} \leq^{5} /{ }_{2}$, then

$\left(\mathrm{F}_{1}\right): \mathrm{F}$ is non-decreasing in $\mathrm{t}_{2}, \mathrm{t}_{5}, \mathrm{t}_{6}$, and

$\left(\mathrm{F}_{2}\right): \mathrm{F}(\mathrm{t}, \mathrm{t}, 0,0, \mathrm{t}, \mathrm{t})=(2-\mathrm{k}) \mathrm{t}<0$, for each $\mathrm{t}>0$, as $\mathrm{k}>2$. So that $\mathrm{F} € \boldsymbol{F}_{6}$.

Note that, $\left(F_{2}\right)$ occurs only for the cases: $\mathrm{x}=\mathrm{c}, \mathrm{y}=\mathrm{a} ; \quad \mathrm{x}=\mathrm{a}, \mathrm{y}=\mathrm{p} ; \quad \mathrm{x}=\mathrm{b}, \mathrm{y}=\mathrm{p}$ and $\mathrm{x}$ $=\mathrm{c}, \mathrm{y}=\mathrm{p}$; where the values of $\mathrm{F}$ are calculated as $2(2-\mathrm{k}),(2-\mathrm{k}) / 4,(2-\mathrm{k}) / 4$ and $1 / 2 \sqrt{7}(2-\mathrm{k})$, respectively. Note that $\mathrm{F}(\mathrm{t}, \mathrm{t}, 0,0, \mathrm{t}, \mathrm{t})<0$, for all $\mathrm{t}>0$, as $\mathrm{k}>2$. Hence $\mathrm{F} € \boldsymbol{F}_{6}$. Further, in rest of the cases $\mathrm{x}=\mathrm{a}, \mathrm{y}=\mathrm{b} ; \mathrm{x}=\mathrm{b}, \mathrm{y}=\mathrm{a} ; \mathrm{x}=\mathrm{a}, \mathrm{y}=\mathrm{c} ; \mathrm{x}=\mathrm{p}, \mathrm{y}=\mathrm{a} ; \mathrm{x}=\mathrm{b}, \mathrm{y}=\mathrm{c}$; $\mathrm{x}=\mathrm{c}, \mathrm{y}=\mathrm{b} ; \mathrm{x}=\mathrm{p}, \mathrm{y}=\mathrm{b}$ and $\mathrm{x}=\mathrm{p}, \mathrm{y}=\mathrm{c}$ the values of $\mathrm{F}$ are: $5-2 \mathrm{k}, 0,5 / 2-\mathrm{k}, 5 / 2-\mathrm{k}$, $5 / 2-\mathrm{k}, 5,53 / 8-(\mathrm{k} \sqrt{5})$ and 5 , respectively. These are non-negative real and hence the inequality (4) is satisfied. Thus, all the conditions of Theorem 3.1 are satisfied and a is the only common fixed point of $\mathrm{A}, \mathrm{B}, \mathrm{S}$ and $\mathrm{T}$ in $\mathrm{X}$.

The following example validates our Theorem 3.2.

EXAMPLE 3.2 Let $X=R_{+}$and $d(x, y)=0$, if $x=y$; and $d(x, y)=\max \{x, y\}$ if $x \neq y$.

Define a real-valued function $\mathrm{F}\left(\mathrm{t}_{1}, \cdots, \mathrm{t}_{6}\right): \mathrm{R}_{+}{ }^{6} \rightarrow \mathrm{R}$ by:

$$
\mathrm{F}\left(\mathrm{t}_{1}, \cdots, \mathrm{t}_{6}\right)=\left[\max \left\{\mathrm{t}_{2}, \mathrm{t}_{3}, \mathrm{t}_{4}, 1 / 2\left(\mathrm{t}_{5}+\mathrm{t}_{6}\right)-\mathrm{t}_{1}\right]-\mathrm{t}_{1} \times \mathrm{t}_{3}\right. \text {. Then, }
$$

$\left(F_{1}\right): \quad F$ is non-decreasing in $t_{2}, t_{5}$ and $t_{6}$.

$\left(F_{2}\right): \quad F(t, t, 0,0, t, t)=-t^{2}<0$, for each $t>0$.

Thus $\mathrm{F} \in \boldsymbol{F}_{6}$. Define the mappings A, B, S, T: X $\rightarrow \mathrm{X}$ by:

$$
\begin{array}{llll}
\mathrm{Ax}=1 /(\mathrm{n}+4), & \mathrm{Bx}=1 /(\mathrm{n}+3), & \mathrm{Sx}=1 /(\mathrm{n}+2), & \mathrm{Tx}=1 /(\mathrm{n}+1), \text { for } \mathrm{n} \\
\mathrm{Ax}=0 . & \mathrm{Bx}=0 . & \mathrm{Sx}=0 . & \mathrm{Tx}=0, \text { otherwise. }
\end{array}
$$

Then we observe that: 
(i) There exist $\mathrm{u} € \mathrm{R}-\{1 / \mathrm{n}\}$ with $\mathrm{n} \geq 1$ such that $\mathrm{ASu}=\mathrm{SAu}$ implies $\mathrm{Au}=\operatorname{Su}$. Hence $(\mathrm{A}, \mathrm{S})$ is (occ). Similarly, $(\mathrm{B}, \mathrm{T})$ is (occ). The set of (occ) of A and S, and B and T are given by: $\operatorname{occ}(\mathrm{A}, \mathrm{S})=\operatorname{occ}(\mathrm{B}, \mathrm{T})=\mathrm{R}-\{1,1 / 2,1 / 3, \cdots\}$.

(ii) Denote $F(x, y)=F(d(A x, B y), d(S x, T y), \cdots, d(A x, T y))$ for all $x, y \in X$.

Let us now show that (4) satisfies for all $x, y$ in $X$. For, let us discuss all the different cases of $x$ and $y$ of $X$, by:

(a) If $x=R-\{1 / m\}$ where $m \geq 1$, and $y=1 / n$ where $n € N$, then $F(x, y)=1 /(n+1)>0$.

(b) If $y=R-\{1 / m\}$ where $m \geq 1$, and $x=1 / n$ where $n € N$, then $F(x, y)=(n+3) /(n+2)(n+4)>0$.

(c) If $x=1 / n=y$, where $n € N$ then $F(x, y)=1 /(n+1)-1 /(n+2)(n+3)>0$.

(d) If $x=1 / n, y=1 / m$, where $m<n$ and $m+3=n+2$ then $F(x, y)=1 /(m+1)-[1 /(m+3)]^{2}>0$.

(e) If $x=1 / n, y=1 / m(m<n)$, where $m, n \in N$ then $F(x, y)=1 /(m+1)-[1 /(m+3)(n+2)]>0$.

(f) If $x=1 / n, y=1 / m(m>n, m+3=n+4)$ then $F(x, y)=1 /(m+1)>0$.

(g) If $x=1 / n, y=1 / m(m>n, m+3>m+1>n+4)$ then $F(x, y)=(n+3) /(n+2)(n+4)>0$.

(h) If $x=1 / n, y=1 / m(m>n, n+4>m+3)$ then $F(x, y)=(m+2) /(n+2)(m+3)>0$.

(i) If $x=1 / n, y=1 / m(m>n, m+3>n+4>m+1)$ then $F(x, y)=(n+3) /(n+2)(n+4)>0$.

(j) For $x=0, y=0$ then $F(x, y)=0$.

The values of metric $d(A x, B y), d(S x, T y), \ldots, d(A x, T y)$ for above cases may be evaluated, for each of the above cases. Observe, from cases (a)-(j) that, $F(x, y) \geq 0$. So the inequality (4) is satisfied. Note that $\mathrm{Au}=\mathrm{Su}=\mathrm{Bv}=\mathrm{Tv}=0$ is the only common fixed point of A, B, S and T. This validates our Theorem 3.2.

\section{REFERENCES}

[1] Lu Z, On common fixed points for converse commuting self-maps on a metric spaces, Acta. Anal. Funct. Appl. 4(3)(2002), 226.

[2] Qui-kuan Liu \& Xin-qi Hu, Some new common fixed point theorems for converse commuting multi-valued mappings in symmetric spaces with applications, Nonlinear Analysis Forum 10(1)(2005), 97.

[3] Popa V, A general fixed point theorem for converse commuting multi-valued map- pings in symmetric spaces, Filomat 21(2) (2007), 267.

[4] Jungck G, Common fixed points for non-continuous non-self mappings on a nonnumeric spaces, Far East J. Math. Sci. 4(2)(1996), 199.

[5] Jungck G \& Rhoades B E, Fixed point theorems for occasionally weakly compatible mappings, Fixed Point Theory 7(2)(2006), 287.

[6] Pathak H K \& Verma R K, Integral type contractive condition for converse commuting mappings, Internat. J. Math. Anal. 3(24)(2009), 1183, MR2604358.

[7] Pathak H K \& Verma R K, An Integral type implicit relation for converse commuting mappings, Internat. J. Math. Anal. 3(24)(2009), 1191. 